Article

\title{
Using CFD Simulation as a Tool to Identify Optimal Operating Conditions for Regeneration of a Catalytic Diesel Particulate Filter
}

\author{
Valeria Di Sarli ${ }^{1, *(1)}$ and Almerinda Di Benedetto ${ }^{2}$ \\ 1 Istituto di Ricerche sulla Combustione, Consiglio Nazionale delle Ricerche (CNR), Piazzale V. Tecchio 80, \\ 80125 Napoli, Italy \\ 2 Dipartimento di Ingegneria Chimica, dei Materiali e della Produzione Industriale, Università degli Studi di \\ Napoli Federico II, Piazzale V. Tecchio 80, 80125 Napoli, Italy \\ * Correspondence: valeria.disarli@irc.cnr.it; Tel.: +39-081-762-2673
}

Received: 10 August 2019; Accepted: 16 August 2019; Published: 21 August 2019

check for updates

Featured Application: The results obtained in this work show that, in order to conduct a safe and effective regeneration of catalytic (i.e., catalyst-coated) diesel particulate filters, it is essential not only to design increasingly active catalysts and to maximize the contact between soot and catalyst, but to also choose operating conditions that allow the prevention of kinetic and oxygen-transport limitations.

\begin{abstract}
In the work presented in this paper, CFD-based simulations of the regeneration process of a catalytic diesel particulate filter were performed with the aim of identifying optimal operating conditions in terms of trade-off between time for regeneration and peak temperature. In the model, all the soot trapped inside the filter was assumed to be in contact with the catalyst. Numerical results have revealed that optimization can be achieved at low inlet gas velocity by taking advantage of the high sensitivity of the soot combustion dynamics to the availability of oxygen. In particular, optimal conditions have been identified when operating with highly active catalysts at sufficiently low inlet gas temperatures, so as to lie on the boundary between kinetics-limited regeneration and oxygen transport-limited regeneration. As catalyst activity is increased, this boundary progressively shifts towards lower inlet gas temperatures, resulting in lower peak temperatures and shorter times for filter regeneration. Under such conditions, in order to further speed up the process while still ensuring temperature control, it is essential to keep the filter adequately hot, thus minimizing the time required for the preheating phase, which may be a significant part (up to $65 \%$ ) of the total time required for regeneration (preheating plus soot consumption).
\end{abstract}

Keywords: catalytic diesel particulate filter; regeneration dynamics; soot-catalyst contact; catalyst activity; operating conditions; kinetic limitations; oxygen-transport limitations; computational fluid dynamics

\section{Introduction}

Catalytic (i.e., catalyst-coated) diesel particulate filters (DPFs) have been proposed to allow regeneration (i.e., oxidation of soot) at low temperatures [1], thus overcoming the drawbacks of the thermal process, including the formation of excessively hot regions that may cause irreversible damage to the filter [2].

The regeneration performance of catalytic DPFs is dependent not only on catalyst activity [3,4], but also on the quality of the contact established between soot and catalyst particles [3-6]. As observed for DPFs wash-coated with nano-metric ceria particles, the soot trapped inside the walls of the filter can come into intimate contact with a well-dispersed catalyst [5,7], whereas this contact remains rather poor 
for the soot cake layer accumulated on top of the walls [5], which represents most of the soot retained in the filter. Although some soot particles in the cake layer may relocate during the regeneration process, possibly coming into contact with the catalyst, most of the soot accumulated as cake remains far from the catalytic walls, thus burning via the thermal path [5]. This may lead to severe temperature excursions also when regenerating catalytic filters.

Spatio-temporal infrared measurements of temperature taken during the combustion process of the cake layer accumulated on planar catalytic single-layer filters have shown that, depending on the operating conditions, two different regimes of regeneration may be established, slow regeneration and fast regeneration [8-10]. In the regime of slow regeneration, combustion of soot occurs uniformly all over the filter, leading to moderate temperature rises. Conversely, in the regime of fast regeneration, combustion of soot occurs via propagation of sharp reaction fronts, resulting in high peak temperatures. Regeneration dynamics evolves from the slow regime to the fast regime as a function of increasing oxygen concentration [8], exhaust gas temperature [9], and soot load [10]. The transition from slow to fast regeneration is rather abrupt $[8,10]$.

Studies on filter regeneration have also been performed by means of models of different complexity. $\mathrm{Yu}$ et al. [11] used a one-dimensional model of a single-channel filter to develop simple criteria for predicting the maximum temperature under both the regimes of slow and fast regeneration. Results of two-dimensional simulations by Mizutani et al. [12] have highlighted the sensitivity of the filter temperature profile to changes in soot load, inlet gas temperature, and, at low flow rate, oxygen concentration. In work by Bensaid et al. [13], the transition from the slow regime to the fast regime with increasing inlet gas temperature was simulated through a three-dimensional CFD-based model of thermal regeneration.

More recently, we proposed a two-dimensional CFD-based model of regeneration of a single-channel catalytic DPF [14], and performed simulations varying the catalyst activity, the inlet gas velocity, and the amount of soot loaded as cake [14-16]. Our attention was mainly focused on the interaction between combustion of the soot trapped inside the catalytic wall of the filter and combustion of the cake. Preliminary results were also obtained in the absence of cake [16]. An abrupt transition from slow to fast regeneration was predicted to occur with increasing catalyst activity $[14,15]$ and soot load [16]. This transition progressively shifts towards higher catalyst activity with increasing inlet gas velocity [15]. In the slow regime, combustion of the cake proceeds independently of combustion of the soot trapped inside the catalytic wall. Regeneration is a "safe" process, but it takes a long time to complete. In the fast regime, the catalytic wall behaves as a "pilot" for the cake, causing its violent ignition. Under such conditions, the time for regeneration is suitable for practical applications. However, the cake burns via a propagating front in an uncontrolled fashion, leading to "runway" of the catalytic filter.

Overall, our model results have shown that, in the presence of cake, it is possible to conduct fast regeneration of the catalytic filter, but not to prevent high temperatures [14-16]. Interestingly, preliminary results have shown that, in the absence of cake, regeneration of the catalytic filter may occur as a low-temperature uniform process taking a time to complete that, even when normalized with respect to the soot load, is lower than the time required for slow regeneration in the presence of cake [16], thus suggesting the chance of identifying optimal operating conditions for a fast but at the same time "safe" regeneration when avoiding the formation of the cake layer. This possibility is also supported by the outcomes of heating-ramp experiments showing that the temperatures required for regenerating catalytic filters decrease with decreasing soot load as a result of improved conditions of soot-catalyst contact $[3,5]$. Indeed, in the absence of cake, the contact between soot and catalyst can be maximized, thus resulting in a truly catalytic regeneration [5,7]. From this perspective, the development of substrates [17] and procedures for their catalyst coating [18] that ensure high filtration efficiencies even at low soot loads, when the mechanism of cake filtration is ruled out and the soot particles are trapped only via deep-bed filtration, becomes a crucial issue. 
In the work presented in this paper, the regeneration dynamics of a catalytic DPF have been deeply investigated with the aim of identifying, in the absence of cake, optimal operating conditions in terms of trade-off between time for regeneration and peak temperature. To this end, CFD-based simulations of soot combustion in a single-channel configuration were performed, varying the catalyst activity and the inlet gas velocity and temperature. The effect of the preheating phase on the regeneration dynamics of the filter has also been assessed. In the model, all the soot trapped inside the wall of the filter was assumed to be in contact with the catalyst.

\section{Mathematical Model}

The CFD-based model developed in Reference [14] was used to run simulations of the regeneration process for a single-channel catalytic DPF. Figure 1 shows the two-dimensional computational domain. The soot was assumed to be trapped only inside the porous wall of the filter, and not even in the form of a cake layer deposited on top of the wall.

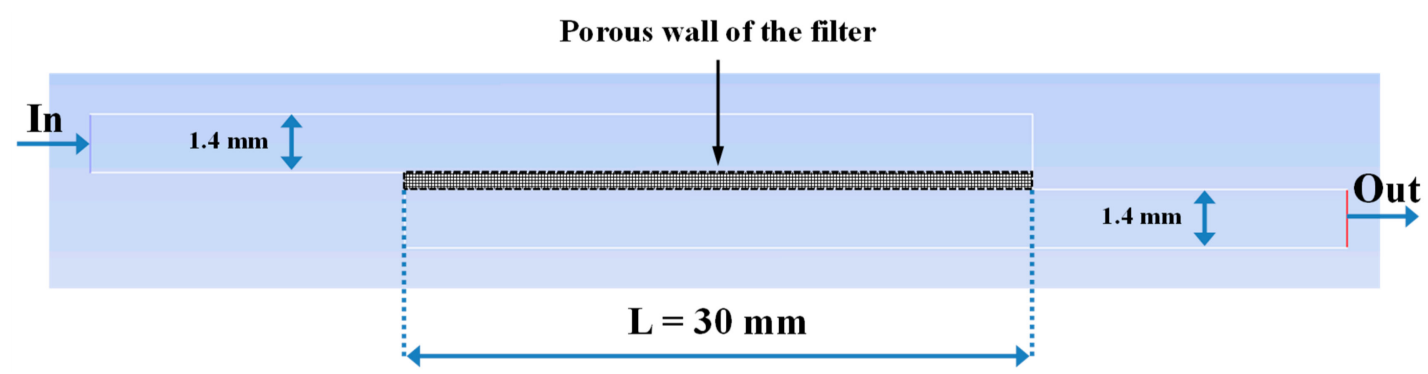

Figure 1. Two-dimensional computational domain (not to scale): single-channel filter (length of the inlet and outlet channels $=45 \mathrm{~mm}$; thickness of the wall $=0.38 \mathrm{~mm}$ ).

The model is described in detail in Reference [14] and here is only briefly presented. The governing fluid flow equations are the mass, momentum, species, and energy conservation equations. In the porous wall, these equations were coupled to the soot conservation equation, and local thermal equilibrium was assumed between the fluid and solid phases (in other words, it was assumed that fluid and solid are at the same temperature). The model equations were solved in "time-dependent" form.

The consumption rate of soot was expressed according to the kinetics obtained by Darcy et al. [19] from experiments of non-catalytic (i.e., thermal) and catalytic oxidation of real diesel soot with oxygen:

$$
r_{\text {total }}=r_{\text {slow_oxidation }}+r_{\text {fast_oxidation }}
$$

with $r_{\text {slow_oxidation }}$ contribution of slow (i.e., thermal) oxidation:

$$
\frac{r_{\text {slow_oxidation }}}{m_{\text {total }, t=0}}=A e^{\left(-E_{a} / R T\right)} \quad\left(x_{\text {Oxygen }}\right)^{a}\left(\frac{m_{\text {total }, t}}{m_{\text {total }, t=0}}\right)^{b}
$$

and $r_{\text {fast_oxidation }}$ contribution of fast (i.e., catalytic) oxidation—-this contribution involves only the soot in contact with the catalyst:

$$
\frac{r_{\text {fast_oxidation }}}{m_{\text {catalyzed }, t=0}}=A^{\prime} e^{\left(-E_{a}^{\prime} / R T\right)} \quad\left(x_{\text {Oxygen }}\right)^{a^{\prime}} \quad\left(\frac{m_{\text {catalyzed }, t}}{m_{\text {catalyzed }, t=0}}\right)^{b^{\prime}}
$$

$x_{\text {Oxygen }}$ (Equations (2) and (3)) is the oxygen mole fraction in the gas phase, $m_{\text {total }}$ (Equation (2)) is the local concentration of soot (all the soot present in the system), and $m_{\text {catalyzed }}$ (Equation (3)) is the local concentration of soot in contact with the catalyst. The values of the kinetic parameters for Equations (2) and (3) are given in Table 1. 
Table 1. Kinetic parameters for Equations (2) and (3) (from Reference [19]).

\begin{tabular}{cccc}
\hline \multicolumn{2}{c}{ Equation (2) } & \multicolumn{2}{c}{ Equation (3) } \\
“Slow" (i.e., Thermal) Oxidation & \multicolumn{2}{c}{ “Fast" (i.e., Catalytic) Oxidation } \\
\hline$A$ & $6.05 \times 10^{7} \mathrm{~s}^{-1}$ & $A^{\prime}\left(=A_{\text {Darcy }}^{\prime}\right.$ & $1.19 \times 10^{5} \mathrm{~s}^{-1}$ \\
$E_{a}$ & $161 \mathrm{~kJ} / \mathrm{mol}$ & $E_{a}^{\prime}$ & $114 \mathrm{~kJ} / \mathrm{mol}$ \\
$a$ & 0.7 & $a^{\prime}$ & 0.3 \\
$b$ & 0.8 & $b^{\prime}$ & 0.8 \\
\hline
\end{tabular}

In the model, all the soot was assumed to be in contact with the catalyst $\left(m_{\text {catalyzed }}=m_{\text {total }}\right)$ and, thus, both contributions (Equations (2) and (3)) were considered for the regeneration kinetics. The (intrinsic) catalyst activity was varied by changing the pre-exponential factor, $A^{\prime}$, in Equation (3). In particular, the ratio, $k$, between $A^{\prime}$ and the pre-exponential factor of the kinetics by Darcy et al. [19],

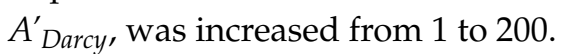

The model was developed in the frame of the porous medium approach of the CFD code ANSYS Fluent 15.0 [20]. A user-defined scalar was used to specify the local soot concentration, whereas the regeneration kinetics was implemented via user-defined subroutines.

The model equations were discretized through the finite-volume method on a grid having about $2.2 \times 10^{5}$ square cells with size equal to $0.025 \mathrm{~mm}$. The spatial discretization and the time integration were performed by using second-order schemes (also for convective terms) and the second-order implicit Crank-Nicholson scheme, respectively.

Fixed flat profiles were assumed as inlet boundary conditions for velocity, species concentration, and temperature. At the outlet boundary, a condition of fixed static pressure was assigned. All the remaining boundaries were assumed to be adiabatic walls.

If not otherwise specified, the simulation (inlet and initial) conditions are those listed in Table 2.

Table 2. Simulation conditions.

\begin{tabular}{ccc}
\hline Parameter & Inlet Value & Initial Value \\
\hline Velocity $[\mathrm{m} / \mathrm{s}]$ & $1^{1}$ & 0 \\
$\mathrm{O}_{2}$ concentration $[\% \mathrm{~mol}]$ & 15 & 15 \\
Temperature $[\mathrm{K}]$ & 813 & 523 \\
Soot concentration $\left[\mathrm{kg} / \mathrm{m}^{3}\right]$ & - & 15 \\
\hline
\end{tabular}

${ }^{1}$ Superficial filtration velocity: $0.047 \mathrm{~m}^{3} / \mathrm{m}^{2} \mathrm{~s}$.

Table 3 gives the values of the properties of the support material (Silicon Carbide, SiC) [21], along with the values of porosity and permeability of the (clean) wall of the filter. A similar value of porosity is reported in Reference [21] for SiC DPFs. The permeability was calculated using the formula reported in Reference [22] for a porous wall made of spherical "grains", the size of which was assumed equal to $24 \mu \mathrm{m}$.

Table 3. Properties of the support material (Silicon Carbide, $\mathrm{SiC}$ ), and porosity and permeability of the (clean) wall of the filter.

\begin{tabular}{cc}
\hline Parameter (Silicon Carbide, SiC) & Value \\
\hline Intrinsic density $\left[\mathrm{kg} / \mathrm{m}^{3}\right]$ & 3240 \\
Specific heat capacity $[\mathrm{J} / \mathrm{kg} \mathrm{K}]$ & 1120 \\
Thermal conductivity $[\mathrm{W} / \mathrm{m} \mathrm{K}]$ & 18 \\
\hline Parameter (Wall of the Filter) & Value \\
\hline Porosity [-] & 0.5 \\
Permeability [m $\left.{ }^{2}\right]$ & $5 \times 10^{-13}$ \\
\hline
\end{tabular}


The initial soot concentration $\left(15 \mathrm{~kg} / \mathrm{m}^{3}\right)$ corresponds to a specific soot load of around $1.8 \mathrm{~kg} / \mathrm{m}^{3}$ (of filter). Experimental results have shown that the walls of $\mathrm{SiC}$ filters wash-coated with a proper amount of nano-metric ceria, so as to preserve the filtering properties of the bare support, allow even higher specific soot loads $\left(\sim 2.5 \mathrm{~kg} / \mathrm{m}^{3}\right)$, while still enabling intimate contact between soot and a highly dispersed catalyst $[5,23]$.

During the computations, the time histories of different variables (temperature, soot concentration and combustion rate, and oxygen mole fraction) were recorded in the monitor points shown in Figure 2.

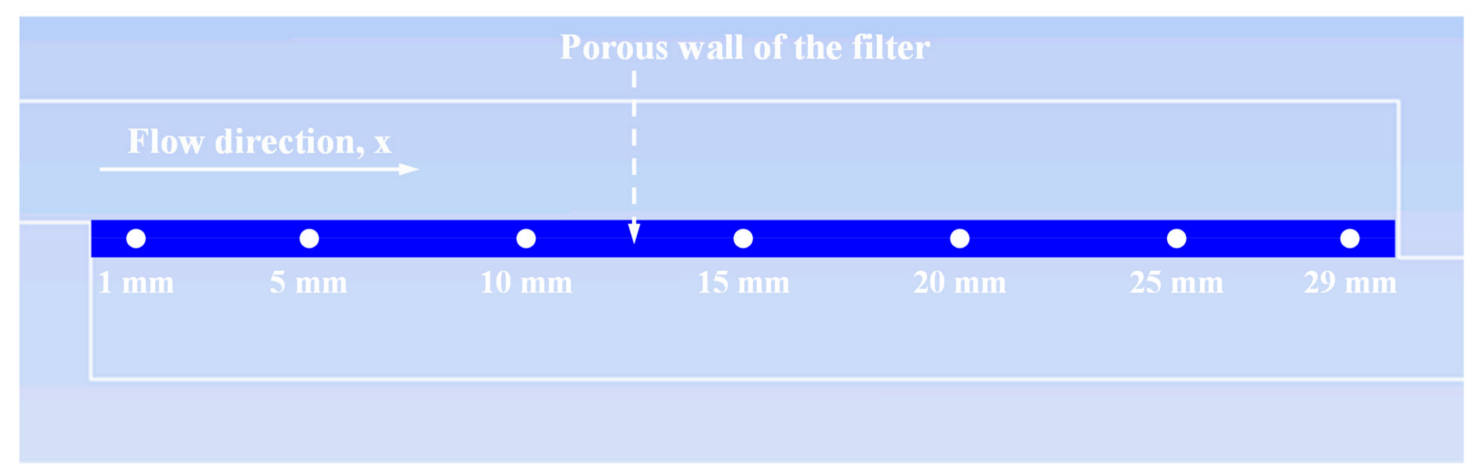

Figure 2. Monitor points.

The highest value of peak temperature recorded in the monitor points of Figure 2 was assumed as the maximum temperature attained in the filter during the regeneration process, $\mathrm{T}_{\max }$. The time for filter regeneration, $t_{\text {reg }}$, was estimated by post-processing the solution data (saved at every $2.5 \mathrm{~s}$ ). In particular, $t_{\text {reg }}$ was assumed as the time at which the volume-averaged conversion of the soot trapped inside the wall of the filter reaches $95 \%$.

\section{Results and Discussion}

\subsection{Effect of the Catalyst Activity}

\subsubsection{Low Inlet Gas Velocity $\left(\mathrm{V}_{\text {in }}=1 \mathrm{~m} / \mathrm{s}\right)$}

Figures 3-7 show the time histories of temperature and soot concentration as recorded in the monitor points of Figure 2 during simulations run at different values of $k$ (i.e., catalyst activity). In these computations, the inlet gas velocity, $\mathrm{V}_{\text {in, }}$ was set equal to $1 \mathrm{~m} / \mathrm{s}$.

The transition from slow to fast regeneration with increasing catalyst activity has already been simulated in the presence of cake $[14,15]$. Figures $3-7$ show that this transition occurs even in the absence of cake. At $k=1$, a regime of slow regeneration is established, according to which combustion of soot is a substantially uniform process all over the filter leading to moderate temperature rises (Figure 3). Conversely, in all the other cases, a regime of fast regeneration is established, with combustion of soot occurring via propagation of the reaction front, thus resulting in high temperature rises (Figures 4-7). In particular, starting from $k=10$, all the soot is burned by a single reaction front moving from upstream to downstream (d wave). At $k=100$ and $k=200$, the regeneration dynamics exhibit the typical features of a process limited by the availability of oxygen [16]. This is further confirmed by Figure 8, showing the time histories of oxygen concentration and soot combustion rate as recorded in the monitor points of Figure 2 at $k=200$. In most of the filter $(x \geq 10 \mathrm{~mm})$, combustion of soot stops when oxygen is depleted. It restarts only when oxygen becomes available again. 


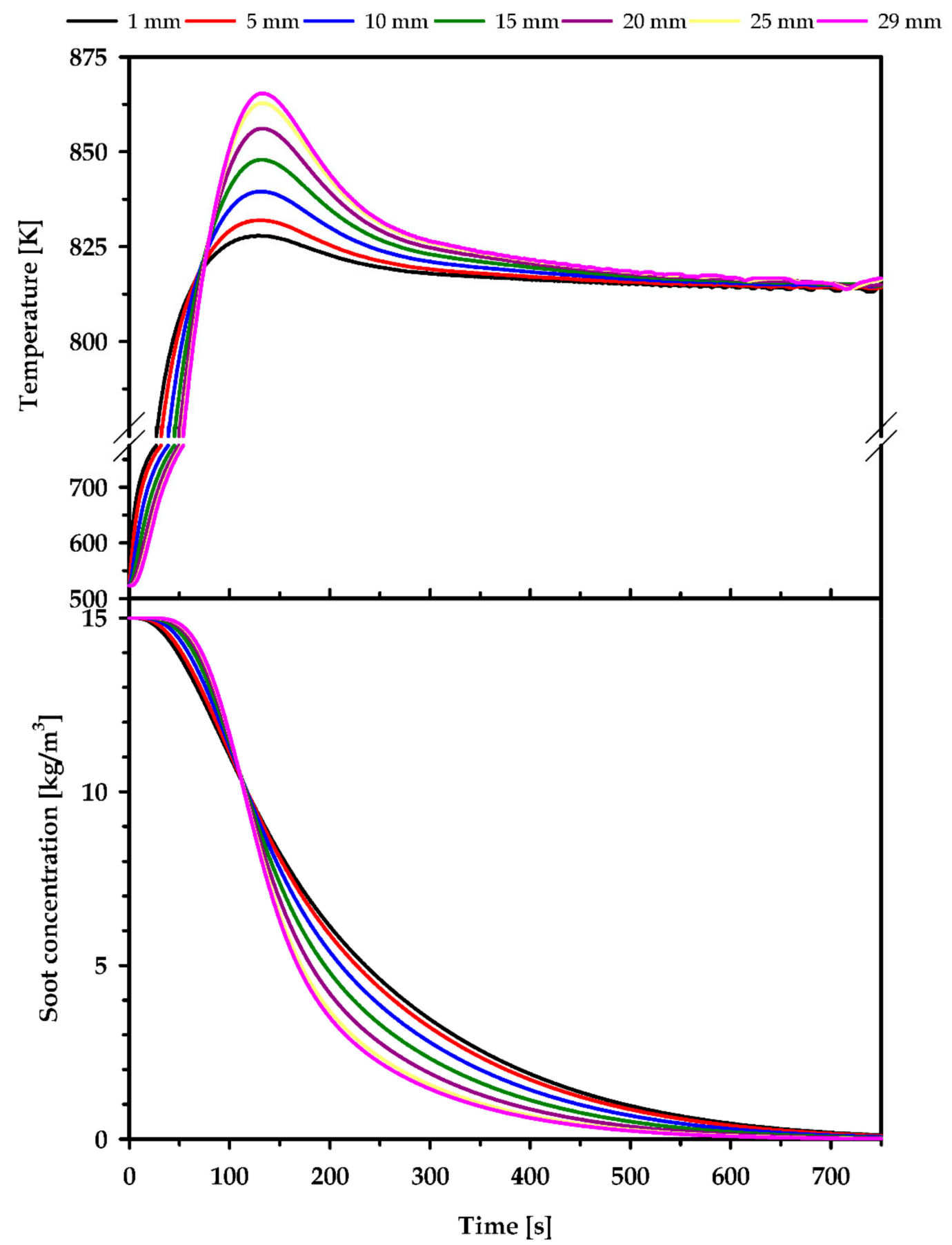

Figure 3. Time histories of temperature and soot concentration (monitor points of Figure 2): $k=1$ (from Reference [16]). 


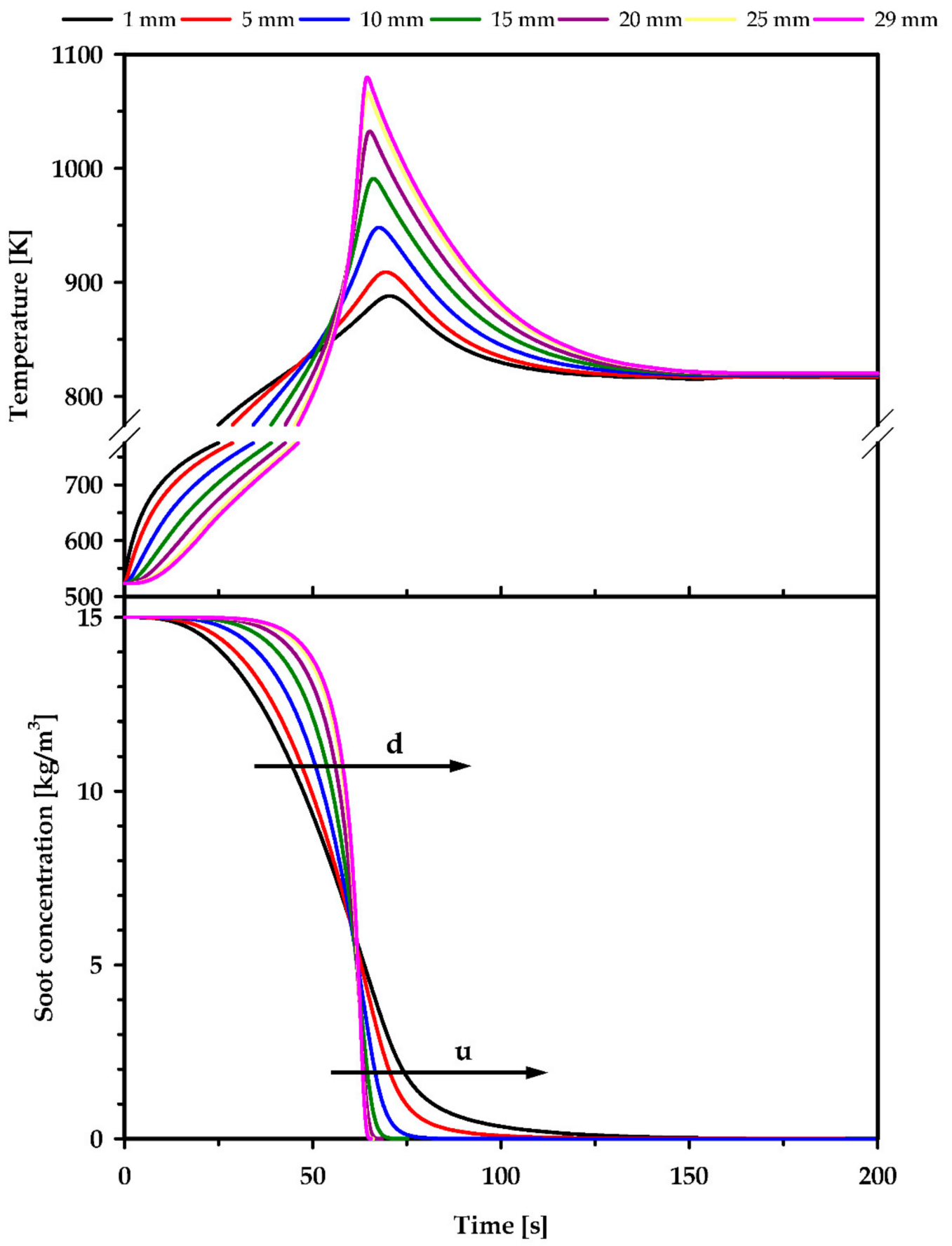

Figure 4. Time histories of temperature and soot concentration (monitor points of Figure 2): $k=5$. The arrows indicate the direction of propagation of the reaction front: $d=$ downstream propagation (from upstream $-1 \mathrm{~mm}$-to downstream-29 $\mathrm{mm}$ ); $\mathrm{u}=$ upstream propagation (from downstream $-29 \mathrm{~mm}$-to upstream-1 $\mathrm{mm}$ ). 


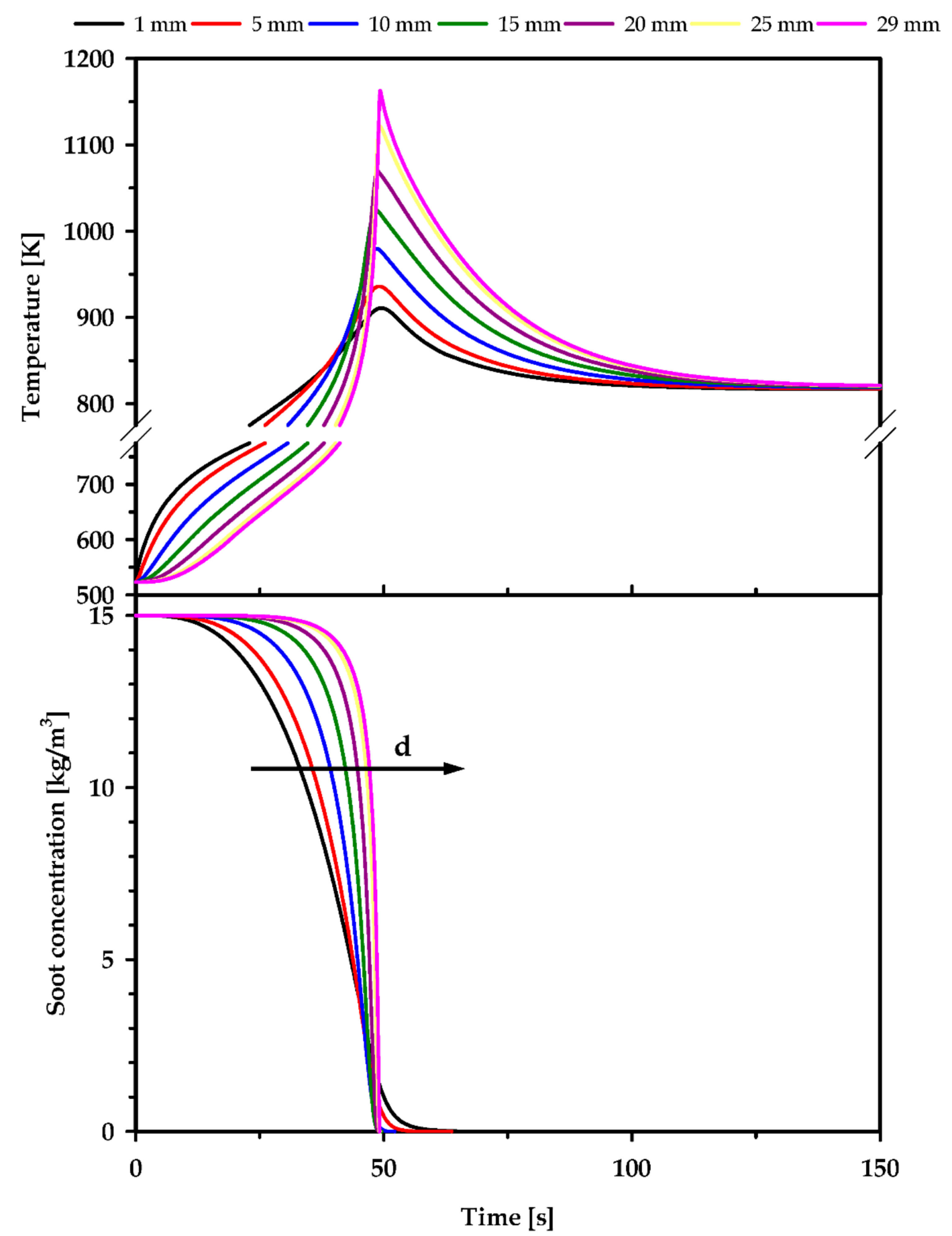

Figure 5. Time histories of temperature and soot concentration (monitor points of Figure 2): $k=10$. The arrow indicates the direction of propagation of the reaction front: $d=$ downstream propagation (from upstream-1 mm-to downstream-29 $\mathrm{mm}$ ). 


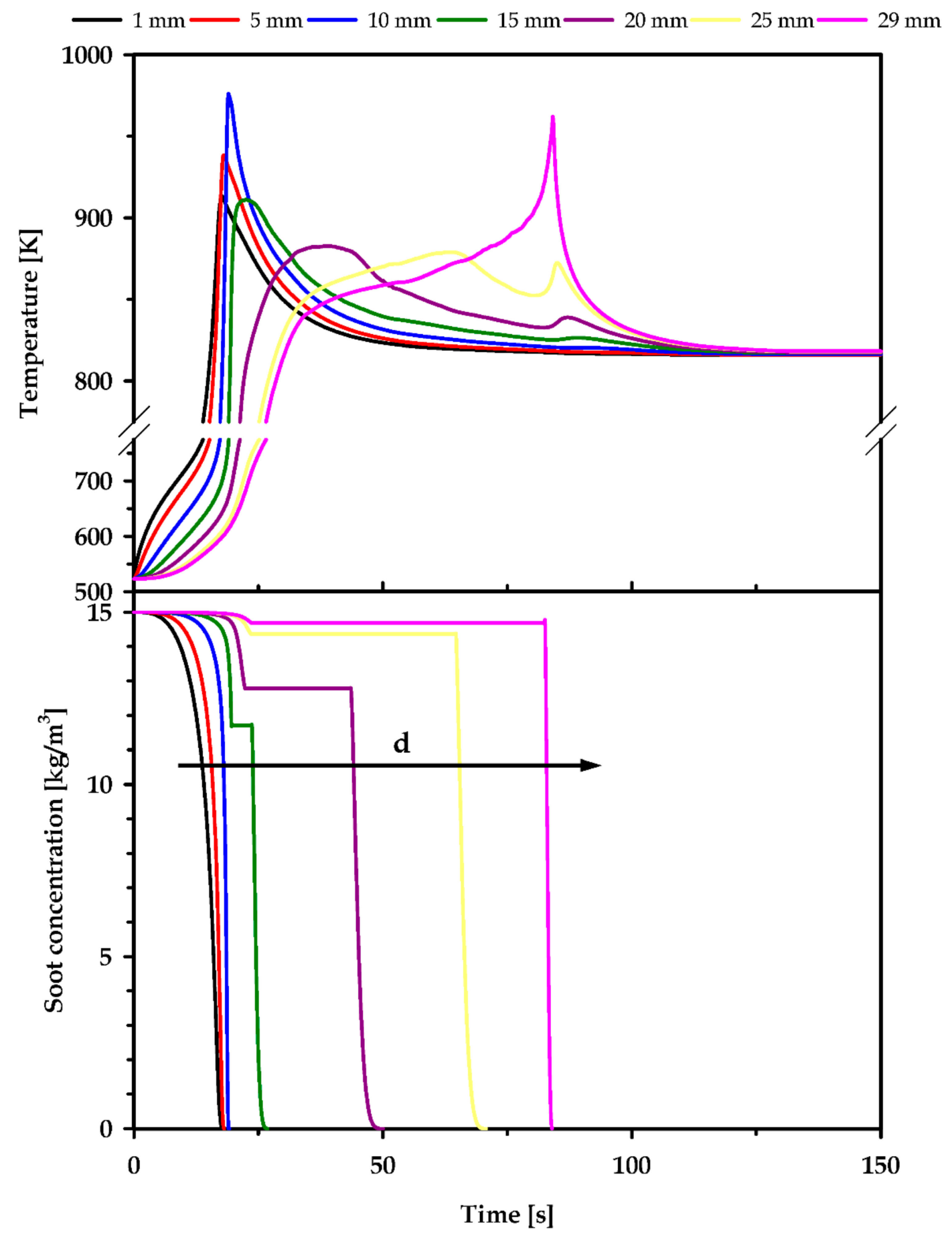

Figure 6. Time histories of temperature and soot concentration (monitor points of Figure 2): $k=100$. The arrow indicates the direction of propagation of the reaction front: $d=$ downstream propagation (from upstream-1 mm-to downstream-29 mm). 


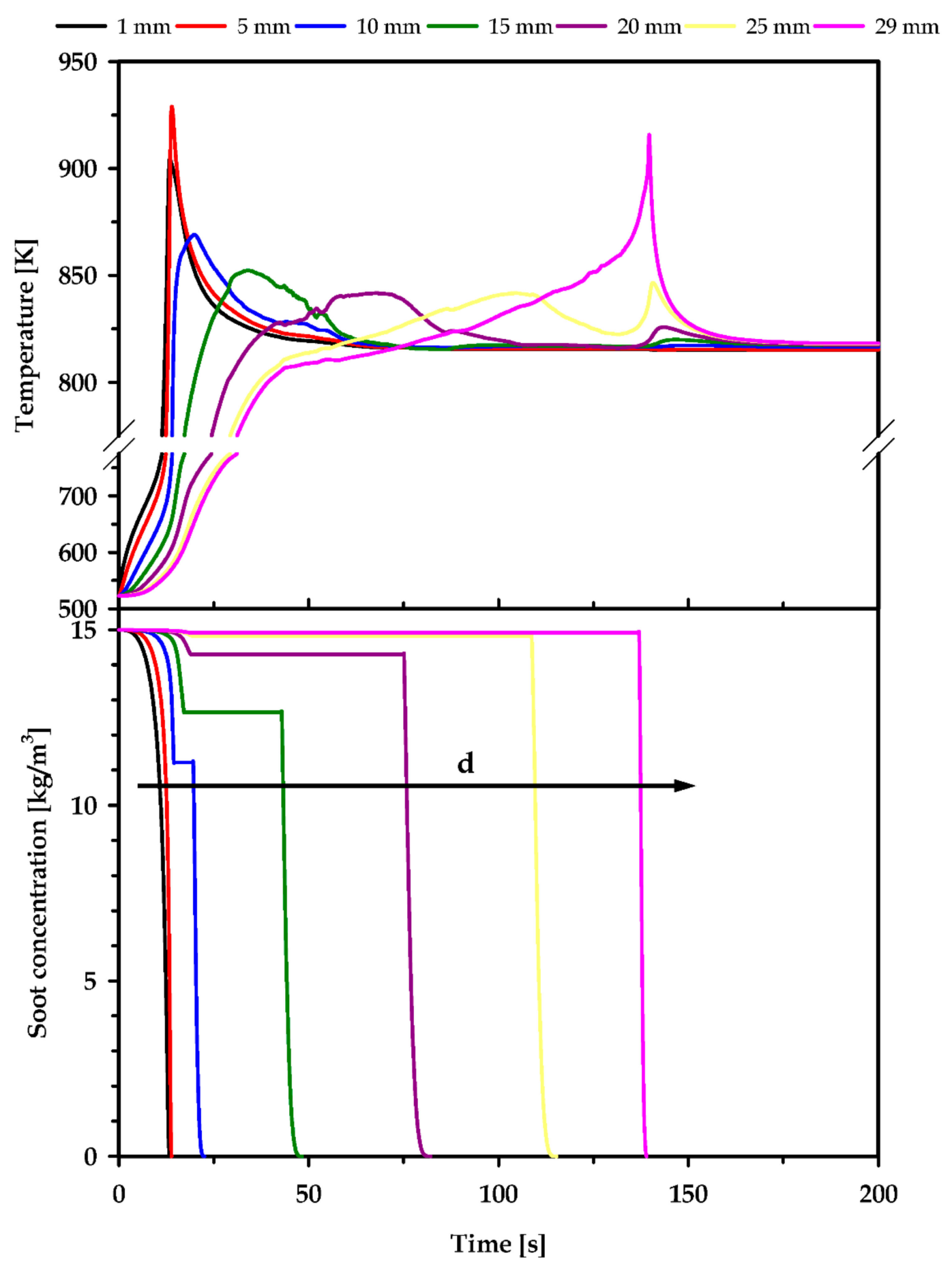

Figure 7. Time histories of temperature and soot concentration (monitor points of Figure 2): $k=200$. The arrow indicates the direction of propagation of the reaction front: $d=$ downstream propagation (from upstream-1 mm-to downstream-29 $\mathrm{mm}$ ). 


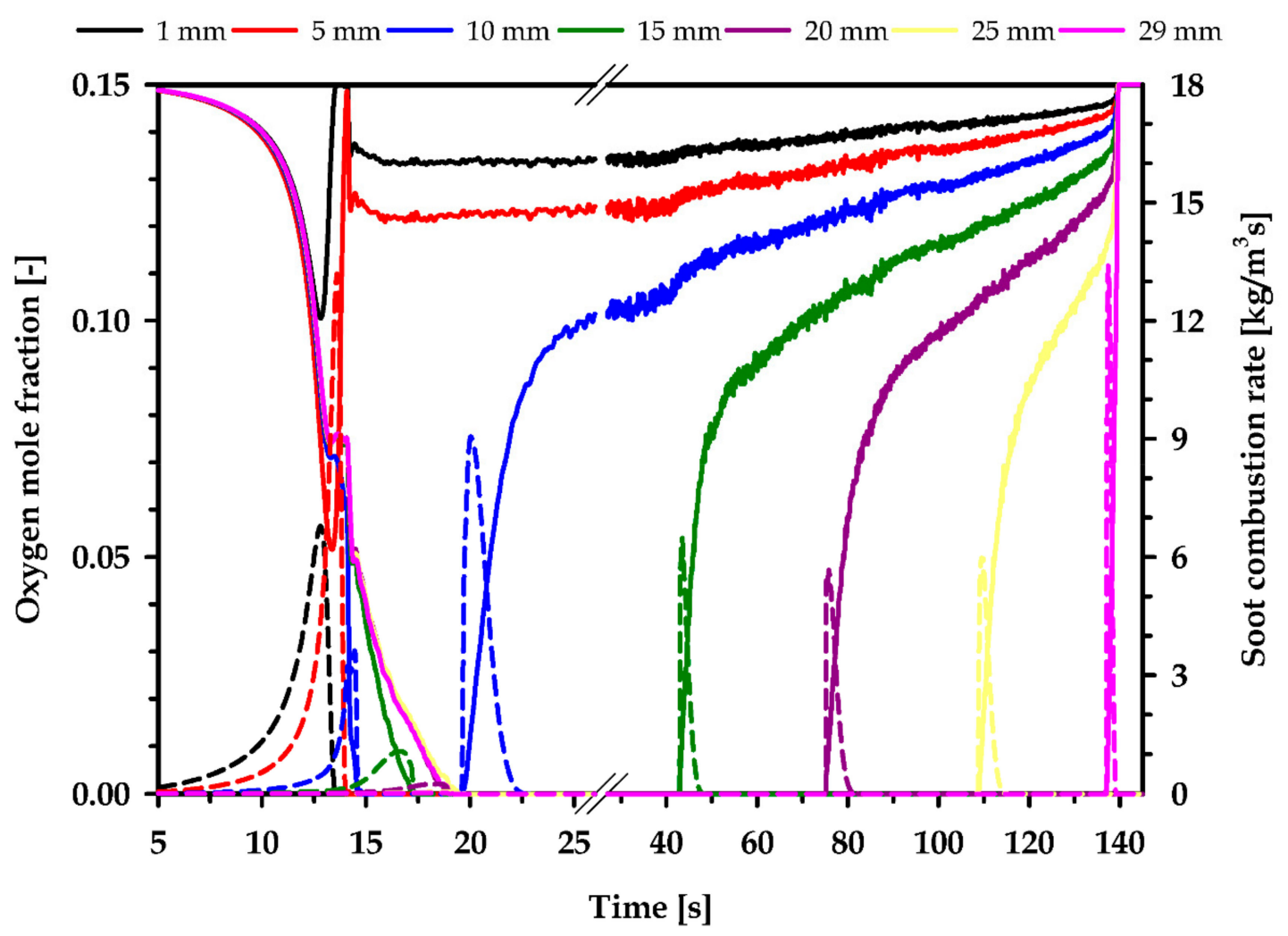

Figure 8. Time histories of oxygen mole fraction (solid lines) and soot combustion rate (dashed lines) (monitor points of Figure 2): $k=200\left(\mathrm{~V}_{\text {in }}=1 \mathrm{~m} / \mathrm{s}\right)$.

\subsubsection{Different Inlet Gas Velocities}

In Figure 9, the maximum temperature attained in the filter during the regeneration process, $\mathrm{T}_{\max }$, and the time for filter regeneration, $\mathrm{t}_{\mathrm{reg}}$, are plotted versus $k$ as obtained from simulations run at different inlet gas velocities $\left(V_{\text {in }}=1 \mathrm{~m} / \mathrm{s} ; 3 \mathrm{~m} / \mathrm{s} ; 5 \mathrm{~m} / \mathrm{s}\right)$.

Regardless of the inlet velocity, the transition from slow to fast regeneration is gradual. Conversely, in the presence of cake, this transition is rather abrupt $[14,15]$.

At $V_{\text {in }}=1 \mathrm{~m} / \mathrm{s}, \mathrm{T}_{\max } / \mathrm{t}_{\text {reg }}$ monotonically increases/decreases with increasing $k$ from 1 to 10 . When $k$ is further increased $(k>10)$, the opposite trends have been simulated, and overall the quantitative features of the regeneration dynamics become much less sensitive to variations in catalyst activity. This behavior is due to the fact that, at low catalyst activity, regeneration takes place according to a kinetics-limited mode, whereas at high catalyst activity, it takes place according to an oxygen transport-limited mode.

In the kinetics-limited mode, regeneration is sensitive to convective heat removal by the gas flowing through the filter. The heat removal increases with increasing inlet gas velocity, thus explaining the trends of decreasing $\mathrm{T}_{\max }$ and increasing $\mathrm{t}_{\mathrm{reg}}$ at low catalyst activity.

As the inlet gas velocity is increased, the transition from the kinetics-limited mode to the oxygen transport-limited mode shifts towards higher values of $k$ (in other words, the oxygen-transport limitations start playing a role at higher catalyst activity). This explains the inversion in the trends of $\mathrm{T}_{\max }$ and $\mathrm{t}_{\text {reg }}$ with the inlet gas velocity in going from low to high catalyst activity. 


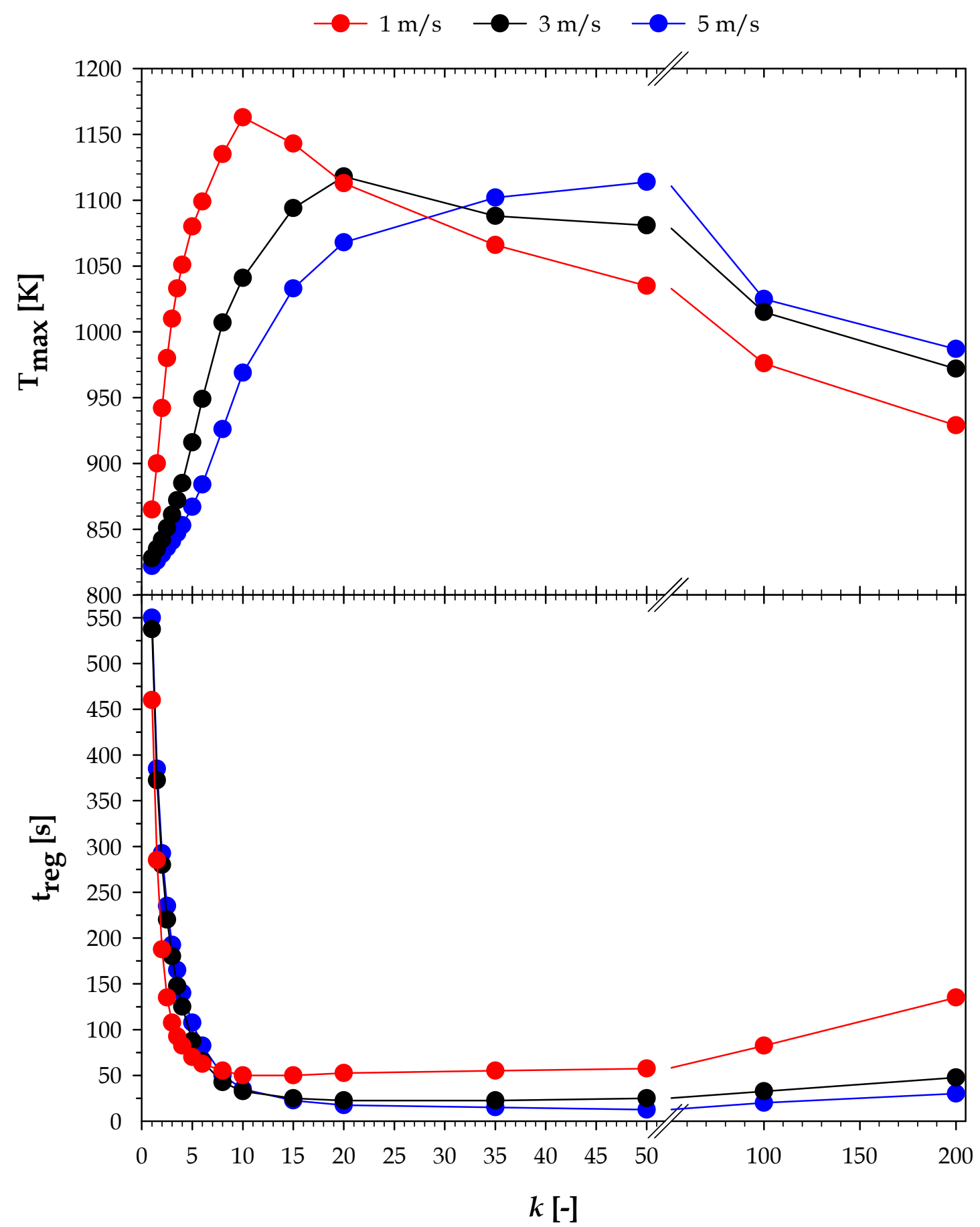

Figure 9. Maximum temperature, $\mathrm{T}_{\max }$, and time for filter regeneration, $\mathrm{t}_{\mathrm{reg}}$, versus $k$ at different inlet gas velocities.

In Figure 10, the results of Figure 9 are shown in the operating map of the filter built in the plane $\mathrm{T}_{\max }$ versus $\mathrm{t}_{\text {reg. }}$.

At $\mathrm{V}_{\text {in }}=1 \mathrm{~m} / \mathrm{s}$, two branches - upper and lower - are well distinguished. In moving from the upper branch $(1 \leq k \leq 10)$ to the lower branch $(10<k \leq 200)$, we go from the kinetics-limited mode to the oxygen transport-limited mode. Under the conditions of this latter mode, regeneration can be conducted at lower temperatures and/or over shorter times than under the conditions of the kinetics-limited mode. 
As the inlet gas velocity is increased (from $1 \mathrm{~m} / \mathrm{s}$ to $5 \mathrm{~m} / \mathrm{s}$ ), the distance between the upper branch and the lower branch decreases, meaning that the potential gain from working at high catalyst activity under the conditions of the oxygen transport-limited mode decreases as well. At $V_{\text {in }}=5 \mathrm{~m} / \mathrm{s}$, the two branches almost overlap and, thus, there is no substantial gain.

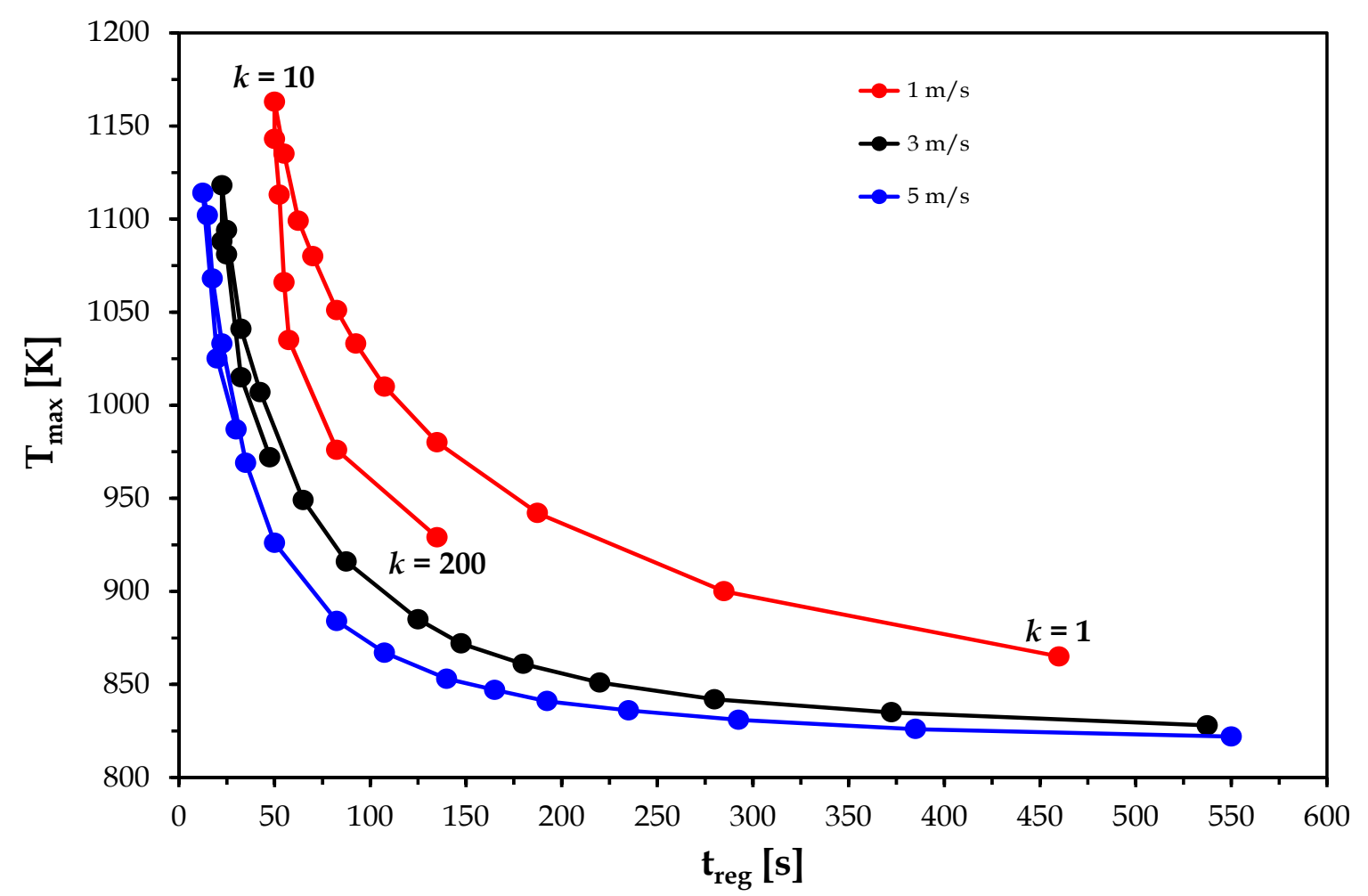

Figure 10. Operating map of the filter in the plane $T_{\max }$ versus $t_{\text {reg }}$ : simulations run by varying the catalyst activity, $k$, at different inlet gas velocities.

\subsection{Effect of the Inlet Gas Temperature}

From this point on, our attention will be focused on the curve at $V_{\text {in }}=1 \mathrm{~m} / \mathrm{s}$ of Figure 10 and, in particular, on its lower branch. In order to identify operating conditions that allow for the further decrease of the maximum temperature and/or the time for filter regeneration, simulations were run at lower values of inlet gas temperature $\left(T_{\text {in }}<813 \mathrm{~K}\right)$. In Figure 11, the results in terms of $T_{\max }$ and $t_{\text {reg }}$ are plotted versus $\mathrm{T}_{\mathrm{in}}$, as obtained at $k=35,50,100$, and 200 .

There are several interesting features shown in this figure. First of all, at each value of $k$, a transition from fast regeneration to slow regeneration is predicted with decreasing $\mathrm{T}_{\mathrm{in}}$. As the value of $k$ is increased, this transition shifts towards lower values of $T_{\text {in }}$.

$\mathrm{T}_{\text {max }} / \mathrm{t}_{\text {reg }}$ monotonically increases/decreases with increasing $\mathrm{T}_{\text {in }}$ until a nearly constant plateau is reached. In addition, at high inlet temperatures, $\mathrm{T}_{\max }$ decreases with increasing $k$, whereas $\mathrm{t}_{\text {reg }}$ slightly increases. Conversely, at low inlet temperatures, $\mathrm{T}_{\max } / \mathrm{t}_{\text {reg }}$ increases/decreases with increasing $k$. These trends suggest that, at high inlet temperatures, regeneration takes place according to the oxygen transport-limited mode, whereas at low inlet temperatures, it takes place according to the kinetics-limited mode.

Once a maximum allowable catalyst temperature is assumed, $\mathrm{T}_{\text {max_allowable, }}$ of $1023 \mathrm{~K}$ (i.e., $750{ }^{\circ} \mathrm{C}$ ) [24], the optimal inlet gas temperature, $\mathrm{T}_{\text {in_optimal }}$, can be identified as the temperature that minimizes regeneration time while still ensuring temperature control (i.e., $\mathrm{T}_{\max } \leq \mathrm{T}_{\text {max_allowable }}$ ). As an example, Figure 12 shows this criterion applied to the case of $k=100$. 


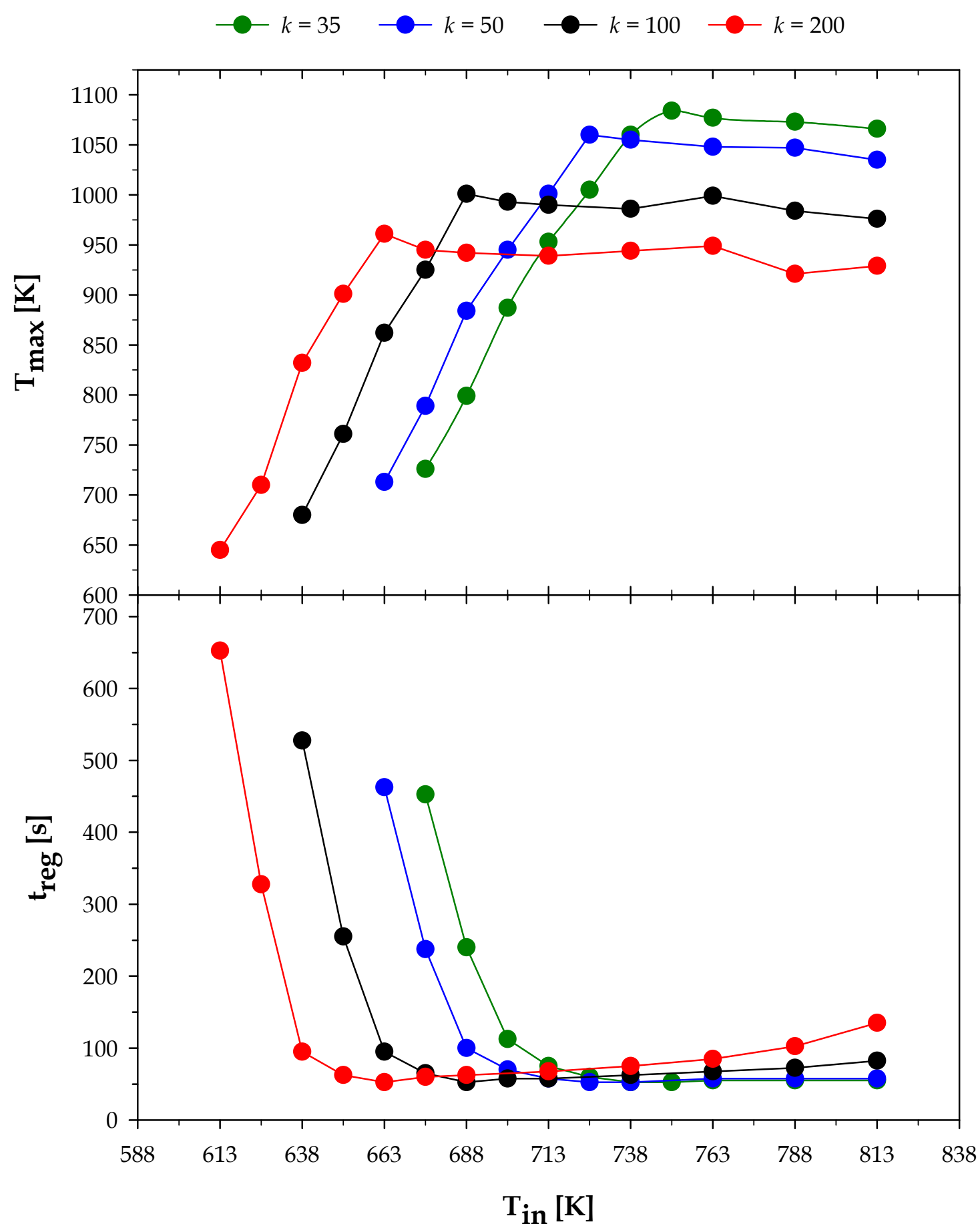

Figure 11. Maximum temperature, $\mathrm{T}_{\max }$, and time for filter regeneration, $\mathrm{t}_{\mathrm{reg}}$, versus inlet gas temperature, $\mathrm{T}_{\mathrm{in}}$, at different values of $k$.

It can be seen that $\mathrm{T}_{\mathrm{in} \_ \text {optimal }}$ lies on the boundary between the oxygen transport-limited mode and the kinetics-limited mode. This also occurs in the cases of $k=35,50$, and 200 (not shown). Under such optimal conditions, the regeneration process is not controlled either by mass transport or by kinetics.

The results of Figure 11 were also rearranged in terms of the objective function, $\phi=t_{\text {reg }} T_{\max }$. Interestingly, it has been found that, at each value of $k, \phi$ exhibits a minimum at $\mathrm{T}_{\text {in }}=\mathrm{T}_{\text {in_optimal }}$.

Figure 13 shows the plot of $\mathrm{T}_{\text {in_optimal }}$ versus $k$.

In Figure 14, $\mathrm{T}_{\max }$ and $\mathrm{t}_{\text {reg }}$ at $\mathrm{T}_{\mathrm{in}}=\mathrm{T}_{\mathrm{in} \_ \text {optimal }}$ are shown as a function of $k$. 
Global assessment of Figures 13 and 14 demonstrates that, as the catalyst activity is increased, the optimal operating point progressively shifts towards lower inlet gas temperatures, resulting in lower peak temperatures and shorter times for filter regeneration.

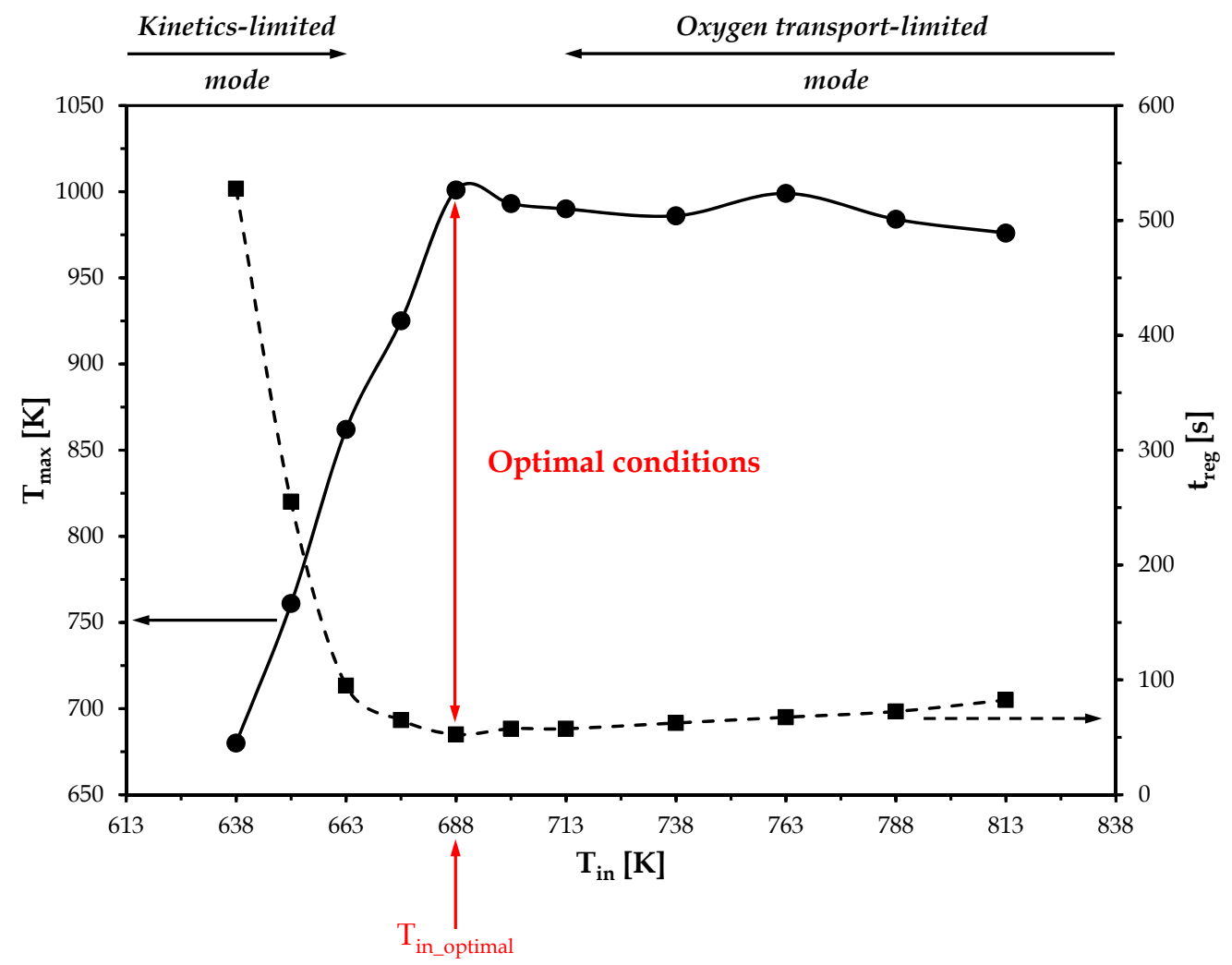

Figure 12. Criterion for the identification of $T_{\text {in_optimal }}$ applied to the case of $k=100: T_{\text {in_optimal }}$ lies on the boundary between the oxygen transport-limited mode and the kinetics-limited mode.

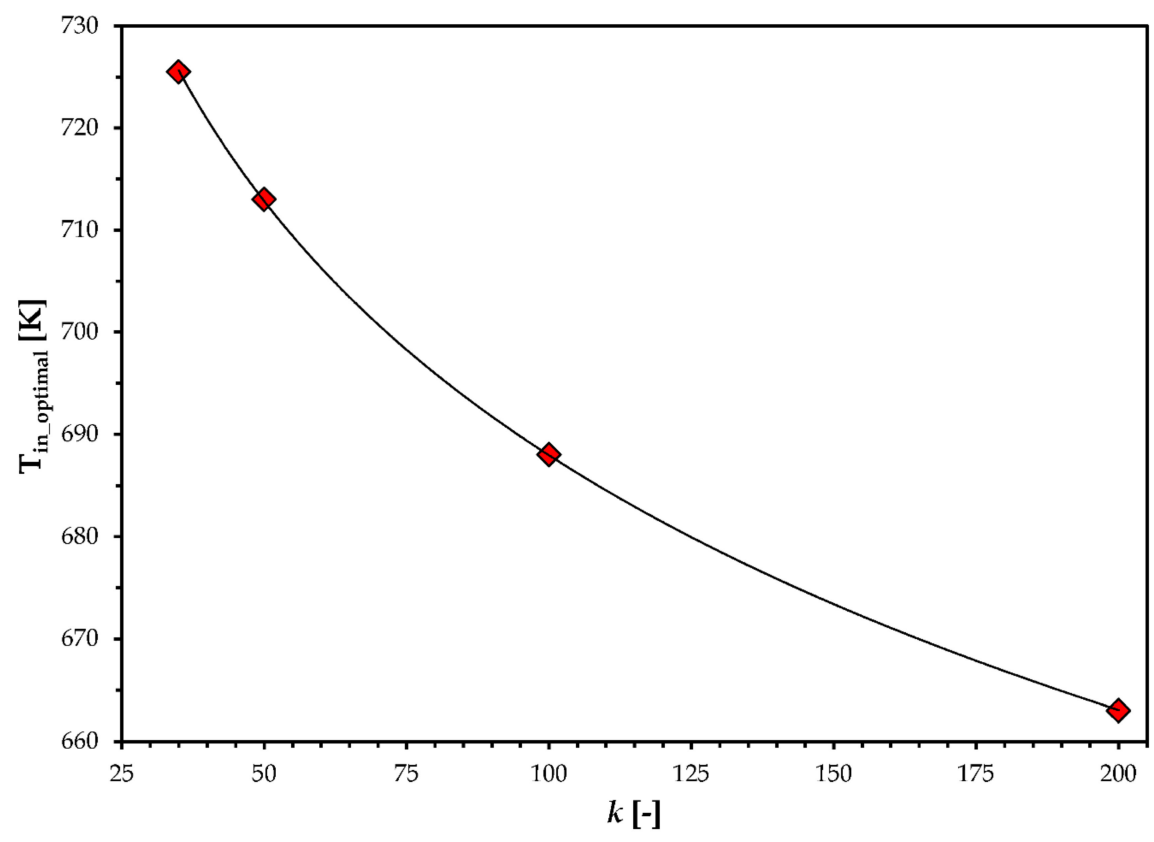

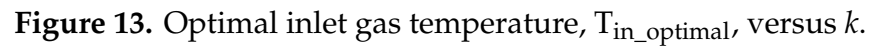




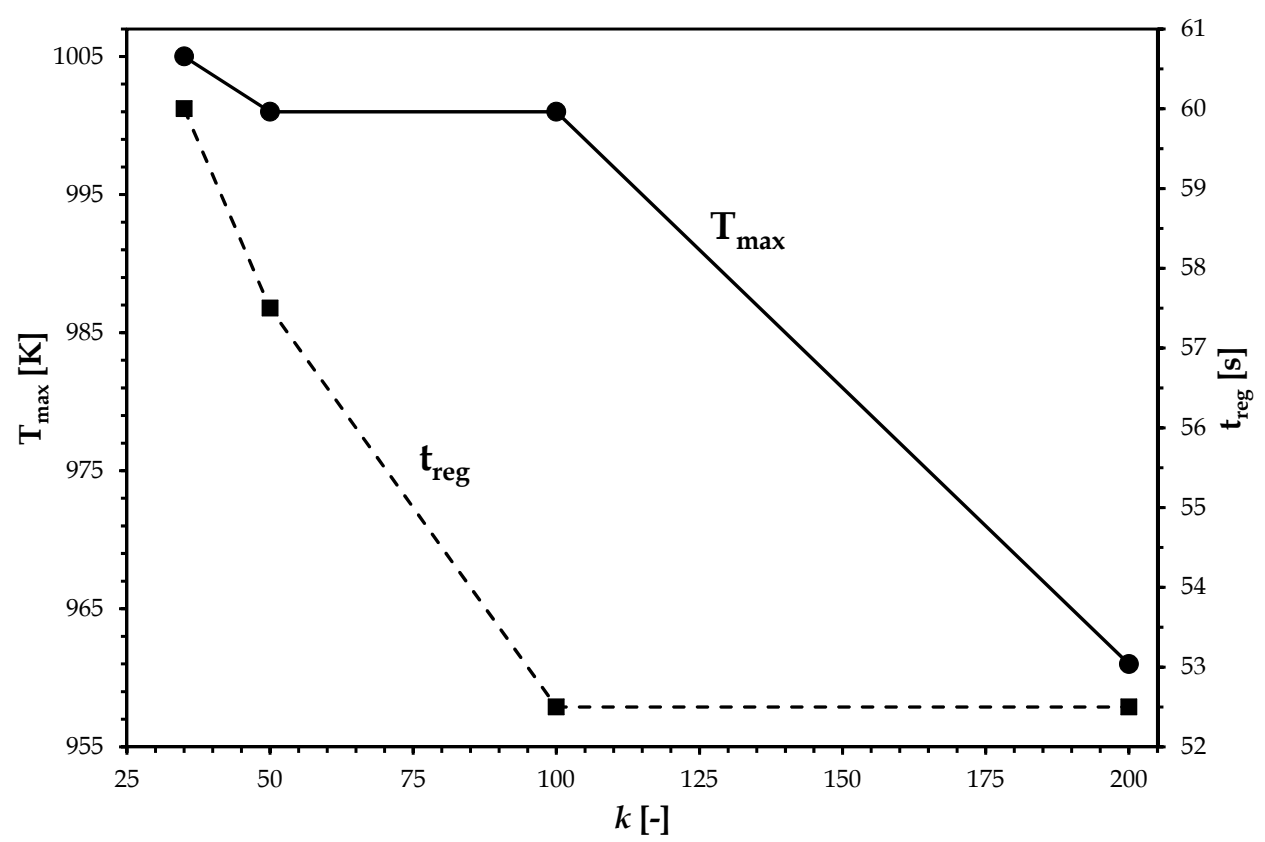

Figure 14. $\mathrm{T}_{\max }$ and $\mathrm{t}_{\mathrm{reg}}$ at $\mathrm{T}_{\mathrm{in}}=\mathrm{T}_{\mathrm{in} \_ \text {optimal }}$ versus $k$.

In Figure 15, the results of Figure 14 are shown in the plane $T_{\max }$ versus $t_{\text {reg }}$ (circles). In this map, the lower branch of the curve at $V_{\text {in }}=1 \mathrm{~m} / \mathrm{s}$ of Figure 10 is also shown. In these computations, $T_{\text {in }}$ was set equal to $813 \mathrm{~K}$.

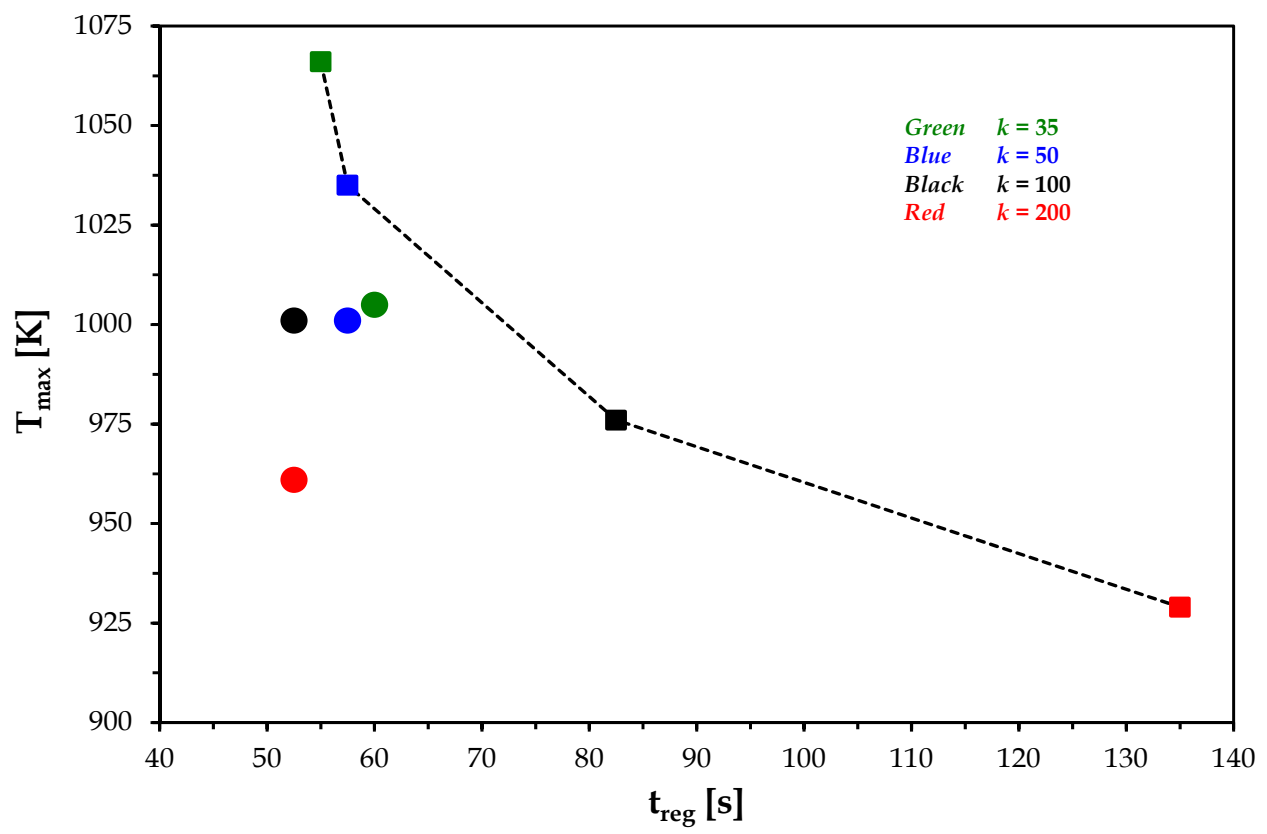

Figure 15. Operating map of the filter in the plane $T_{\max }$ versus $t_{\text {reg }}$ : results at $T_{\text {in }}=T_{\text {in_optimal }}$ for different values of $k$ (circles). The lower branch of the curve at $V_{\text {in }}=1 \mathrm{~m} / \mathrm{s}$ of Figure 10 is also shown $\left(\mathrm{T}_{\text {in }}=813 \mathrm{~K}\right)$.

At $k=35$ and 50 , the main effect of decreasing the inlet gas temperature from $813 \mathrm{~K}$ to the optimal value is lowering $\mathrm{T}_{\max }$. Conversely, at $k=100$ and 200, the main effect is lowering $\mathrm{t}_{\text {reg }}$.

It is worth remembering that our simulations were run assuming the cake to be absent, and that all the soot trapped inside the wall of the filter is in contact with the catalyst. In real-world applications, the accumulation of ash, which is considered as one of the greatest challenges [25,26], will tend to 
progressively complicate the conditions of soot-catalyst contact and, although the ash itself may have a catalytic effect on soot [27], this will impact on the regeneration performance of the catalytic filter, even when starting with high catalyst activity (i.e., high values of $k$ ).

\subsection{Effect of the Preheating Phase}

The regeneration process consists of two phases in series. The first phase is that of preheating, the initial temperature of the filter ( $523 \mathrm{~K}$ in our simulations) being lower than the inlet gas temperature. The second phase is that of true soot consumption. Therefore, the (total) time for filter regeneration, $t_{\text {reg }}$, is the sum of two contributions, the time for preheating and the time for soot consumption.

In Table 4 , the time for preheating, $t_{\text {preheat }}$, is given, along with $t_{\text {reg }}$ and the $t_{\text {preheat }} / t_{\text {reg }}$ ratio, as calculated at $T_{\text {in }}=T_{\text {in_optimal }}$ for different values of $k$. $t_{\text {preheat }}$ was assumed as the time at which the volume-averaged conversion of the soot trapped inside the wall of the filter reaches $10 \%$ (whereas, $t_{\text {reg }}$ was assumed as the time at which the volume-averaged soot conversion reaches $95 \%$ ).

Table 4. Time for preheating, $t_{\text {preheat }}$, time for filter regeneration, $t_{\text {reg }}$, and $t_{\text {preheat }} / t_{\text {reg }}$ ratio, as calculated at $\mathrm{T}_{\mathrm{in}}=\mathrm{T}_{\mathrm{in} \_ \text {optimal }}$ for different values of $k$.

\begin{tabular}{cccc}
\hline $\boldsymbol{k}[-]$ & $\mathbf{t}_{\text {preheat }}[\mathbf{s}]$ & $\mathbf{t}_{\text {reg }}[\mathbf{s}]$ & $\mathbf{t}_{\text {preheat }} / \mathbf{t}_{\text {reg }}[-]$ \\
\hline $\mathbf{3 5}$ & 37.5 & 60.0 & 0.625 \\
$\mathbf{5 0}$ & 37.5 & 57.5 & 0.652 \\
$\mathbf{1 0 0}$ & 35.0 & 52.5 & 0.667 \\
$\mathbf{2 0 0}$ & 32.5 & 52.5 & 0.619 \\
\hline
\end{tabular}

$t_{\text {preheat }}$ is a significant part (up to $65 \%$ ) of $t_{\text {reg. }}$. In order to assess the effect of the preheating phase on the regeneration dynamics of the filter, computations were run at higher initial temperatures $(>523 \mathrm{~K})$. In particular, at each value of $k$, the initial temperature was set equal to the inlet gas temperature $\left(=\mathrm{T}_{\text {in_optimal }}\right)$, thus avoiding the phase of preheating. The operating map of Figure 16 shows the comparison between the results obtained with (full circles) and without (empty circles) preheating.

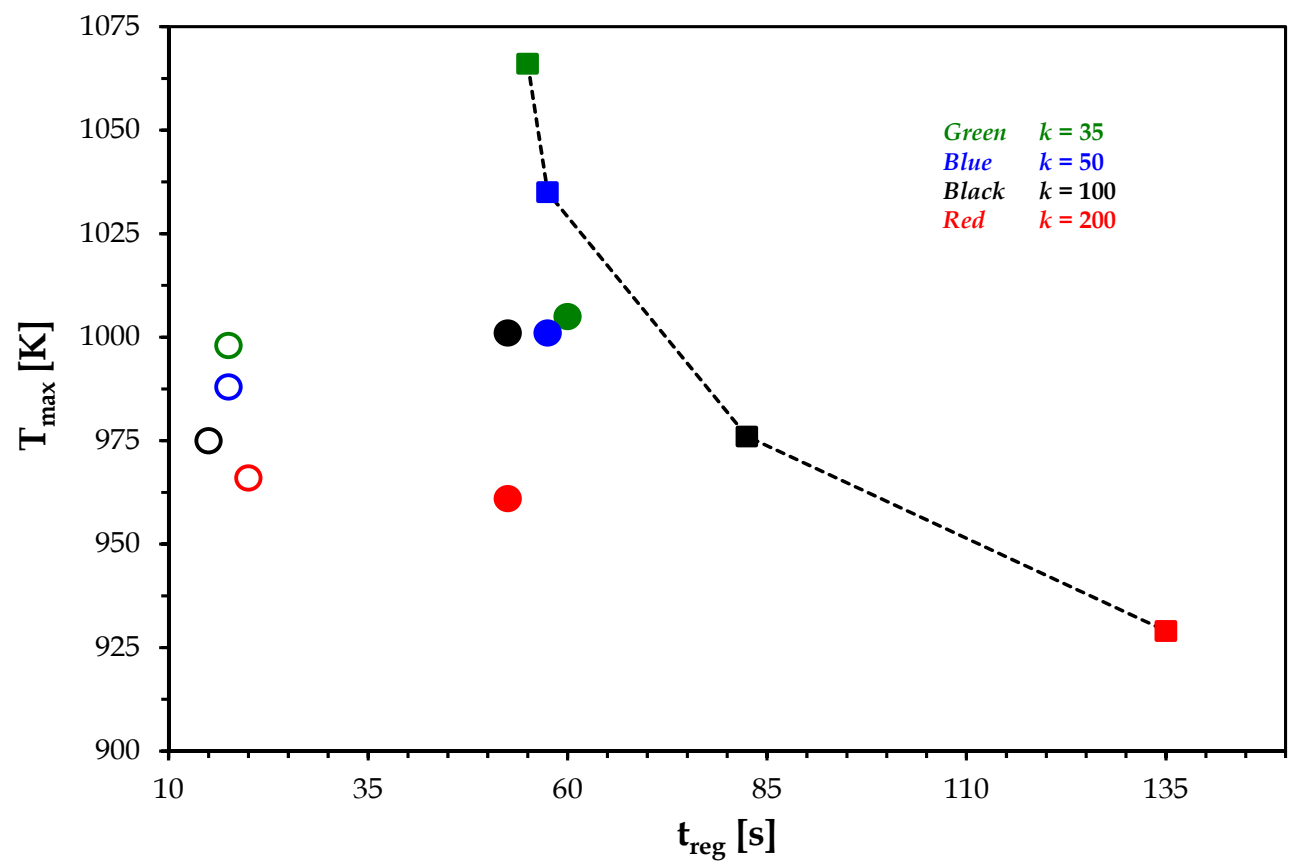

Figure 16. Operating map of the filter in the plane $T_{\max }$ versus $t_{\text {reg: }}$ : results at $T_{\text {in }}=T_{\text {in_optimal }}$ with (full circles) and without (empty circles) preheating for different values of $k$. The lower branch of the curve at $V_{\text {in }}=1 \mathrm{~m} / \mathrm{s}$ of Figure 10 is also shown. 
At each value of $k$, when avoiding the preheating of the filter, regeneration becomes much faster, but the peak temperature is slightly affected.

\section{Conclusions}

CFD-based simulations of the regeneration process of a single-channel catalytic DPF were performed assuming the soot cake layer to be absent, and that all the soot trapped inside the wall of the filter is in contact with the catalyst. The obtained results have shown that it is possible to identify optimal operating conditions in terms of trade-off between time for regeneration and peak temperature. This optimization can be achieved at low inlet gas velocity by taking advantage of the high sensitivity of the regeneration dynamics to the availability of oxygen. In particular, optimal conditions have been identified when operating with highly active catalysts at sufficiently low inlet gas temperatures, so as to lie on the boundary between kinetics-limited regeneration and oxygen transport-limited regeneration. As catalyst activity is increased, this boundary progressively shifts towards lower inlet gas temperatures, resulting in lower peak temperatures and shorter times for filter regeneration. Under such conditions, in order to further speed up the process while still ensuring temperature control, it is essential to keep the filter adequately hot, thus minimizing the time required for the preheating phase, which may be a significant part (up to $65 \%$ ) of the total time required for regeneration (preheating plus soot consumption).

On the basis of these results, it can be concluded that, in order to conduct a safe and effective regeneration of catalytic DPFs, it is essential not only to design increasingly active catalysts and to maximize the soot-catalyst contact inside the walls of the filter, but also to properly choose the operating conditions.

Author Contributions: Conceptualization, V.D.S. and A.D.B.; Methodology, V.D.S. and A.D.B.; Software, V.D.S.; Validation, V.D.S.; Investigation, V.D.S.; Resources, V.D.S. and A.D.B.; Data curation, V.D.S.; Visualization, V.D.S. and A.D.B.; Writing—original draft, V.D.S.; Writing-review \& editing, V.D.S. and A.D.B.

Funding: This research received no external funding.

Acknowledgments: Vincenzo Smiglio and Luigi Muriello are gratefully acknowledged for their technical assistance in the computing activity.

Conflicts of Interest: The authors declare no conflict of interest.

\section{References}

1. Fino, D.; Bensaid, S.; Piumetti, M.; Russo, N. A review on the catalytic combustion of soot in diesel particulate filters for automotive applications: From powder catalysts to structured reactors. Appl. Catal. A Gen. 2016, 509, 75-96. [CrossRef]

2. Yang, K.; Fox, J.T.; Hunsicker, R. Characterizing diesel particulate filter failure during commercial fleet use due to pinholes, melting, cracking, and fouling. Emiss. Control Sci. Technol. 2016, 2, 145-155. [CrossRef]

3. Rico Pérez, V.; Bueno-López, A. Catalytic regeneration of diesel particulate filters: Comparison of Pt and CePr active phases. Chem. Eng. J. 2015, 279, 79-85. [CrossRef]

4. Nascimento, L.F.; Lima, J.F.; de Sousa Filho, P.C.; Serra, O.A. Effect of lanthanum loading on nanosized $\mathrm{CeO}_{2}-\mathrm{ZnO}$ solid catalysts supported on cordierite for diesel soot oxidation. J. Environ. Sci. 2018, 73, 58-68. [CrossRef] [PubMed]

5. Di Sarli, V.; Landi, G.; Lisi, L.; Saliva, A.; Di Benedetto, A. Catalytic diesel particulate filters with highly dispersed ceria: Effect of the soot-catalyst contact on the regeneration performance. Appl. Catal. B Environ. 2016, 197, 116-124. [CrossRef]

6. Su, C.; Wang, Y.; Kumar, A.; McGinn, P.J. Simulating real world soot-catalyst contact conditions for lab-scale catalytic soot oxidation studies. Catalysts 2018, 8, 247. [CrossRef]

7. Di Sarli, V.; Landi, G.; Lisi, L.; Di Benedetto, A. Ceria-coated diesel particulate filters for continuous regeneration. AIChE J. 2017, 63, 3442-3449. [CrossRef]

8. Chen, K.; Martirosyan, K.S.; Luss, D. Soot combustion dynamics in a planar diesel particulate filter. Ind. Eng. Chem. Res. 2009, 48, 3323-3330. [CrossRef] 
9. Chen, K.; Martirosyan, K.S.; Luss, D. Transient temperature rise during regeneration of diesel particulate filters. Chem. Eng. J. 2011, 176-177, 144-150. [CrossRef]

10. Martirosyan, K.S.; Chen, K.; Luss, D. Behavior features of soot combustion in diesel particulate filter. Chem. Eng. Sci. 2010, 1, 42-46. [CrossRef]

11. Yu, M.; Luss, D.; Balakotaiah, V. Regeneration modes and peak temperatures in a diesel particulate filter. Chem. Eng. J. 2013, 232, 541-554. [CrossRef]

12. Mizutani, T.; Watanabe, Y.; Yuuki, K.; Hashimoto, S.; Hamanaka, T.; Kawashima, J. Soot Regeneration Model for SiC-DPF System Design; SAE Technical Paper; 2004-01-0159; SAE International: Warrendale, PA, USA, 2004.

13. Bensaid, S.; Marchisio, D.L.; Fino, D. Numerical simulation of soot filtration and combustion within diesel particulate filters. Chem. Eng. Sci. 2010, 65, 357-363. [CrossRef]

14. Di Sarli, V.; Di Benedetto, A. Modeling and simulation of soot combustion dynamics in a catalytic diesel particulate filter. Chem. Eng. Sci. 2015, 137, 69-78. [CrossRef]

15. Di Sarli, V.; Di Benedetto, A. Operating map for regeneration of a catalytic diesel particulate filter. Ind. Eng. Chem. Res. 2016, 55, 11052-11061. [CrossRef]

16. Di Sarli, V.; Di Benedetto, A. Combined effects of soot load and catalyst activity on the regeneration dynamics of catalytic diesel particulate filters. AIChE J. 2018, 64, 1714-1722. [CrossRef]

17. Orihuela, M.P.; Gómez-Martín, A.; Miceli, P.; Becerra, J.A.; Chacartegui, R.; Fino, D. Experimental measurement of the filtration efficiency and pressure drop of wall-flow diesel particulate filters (DPF) made of biomorphic Silicon Carbide using laboratory generated particles. Appl. Therm. Eng. 2018, 131, 41-53. [CrossRef]

18. Rossomando, B.; Arsie, I.; Meloni, E.; Palma, V.; Pianese, C. Experimental Tests on the Feasibility of Passive Regeneration in a Catalytic DPF at the Exhaust of a Light-Duty Diesel Engine; SAE Technical Paper; 2019-24-0045; SAE International: Warrendale, PA, USA, 2019.

19. Darcy, P.; Da Costa, P.; Mellottée, H.; Trichard, J.-M.; Djéga-Mariadassou, G. Kinetics of catalyzed and non-catalyzed oxidation of soot from a diesel engine. Catal. Today 2007, 119, 252-256. [CrossRef]

20. ANSYS Fluent Theory Guide (Release 15.0); ANSYS Inc.: Canonsburg, PA, USA, 2013; Available online: http://www.ansys.com (accessed on 28 May 2019).

21. Bensaid, S.; Caroca, C.J.; Russo, N.; Fino, D. Detailed investigation of non-catalytic DPF regeneration. Can. J. Chem. Eng. 2011, 89, 401-407. [CrossRef]

22. Konstandopoulos, A.G. Flow Resistance Descriptors for Diesel Particulate Filters: Definitions, Measurements and Testing; SAE Technical Paper; 2003-01-0846; SAE International: Warrendale, PA, USA, 2003.

23. Di Sarli, V.; Landi, G.; Lisi, L.; Di Benedetto, A. Highly dispersed ceria for catalytic regeneration of diesel particulate filter. Adv. Sci. Lett. 2017, 23, 5909-5911. [CrossRef]

24. Piumetti, M.; Bensaid, S.; Russo, N.; Fino, D. Nanostructured ceria-based catalysts for soot combustion: Investigations on the surface sensitivity. Appl. Catal. B Environ. 2015, 165, 742-751. [CrossRef]

25. Liu, Y.; Su, C.; Clerc, J.; Harinath, A.; Rogoski, L. Experimental and Modeling Study of Ash Impact on DPF Backpressure and Regeneration Behaviors; SAE Technical Paper; 2015-01-1063; SAE International: Warrendale, PA, USA, 2015.

26. Su, C.; Brault, J.; Munnannur, A.; Liu, Z.G.; Milloy, S.; Harinath, A.; Dunnuck, D.; Federle, K. Model-Based Approaches in Developing an Advanced Aftertreatment System: An Overview; SAE Technical Paper; 2019-01-0026; SAE International: Warrendale, PA, USA, 2019.

27. Du, Y.; Meng, Z.; Fang, J.; Qin, Y.; Jiang, Y.; Li, S.; Li, J.; Chen, C.; Bai, W. Characterization of soot deposition and oxidation process on catalytic diesel particulate filter with ash loading through an optimized visualized method. Fuel 2019, 243, 251-261. [CrossRef]

(C) 2019 by the authors. Licensee MDPI, Basel, Switzerland. This article is an open access article distributed under the terms and conditions of the Creative Commons Attribution (CC BY) license (http://creativecommons.org/licenses/by/4.0/). 